\title{
Um esboço sobre a realidade da gurizada das margens do Arroio \\ Santa Bárbara a partir da fotografia como jogo de linguagem
}

\author{
Un esbozo sobre la realidad de la gurizada de las márgenes del \\ Arroyo \\ Santa Bárbara a partir de la fotografía como juego de \\ lenguaje
}

A sketch on the reality of the gurizada on the banks of the Santa
Barbara creek from the photography like game of language

Heloisa Helena Duval de Azevedo ${ }^{1}$

\begin{abstract}
Resumo
Nosso estudo se deteve sobre um recorte da realidade, utilizando fotografias, a partir do projeto de extensão sobre reforço escolar que estava inserido no Programa de Extensão, entre os anos de 2006 e 2010, "Ação interdisciplinar de atenção integral a carroceiros e catadores de lixo que trabalham às margens do arroio Santa Bárbara em Pelotas" sob a responsabilidade da Faculdade de Veterinária/UFPel e da FaE/UFPel. A comunidade ainda é caracterizada como de vulnerabilidade social extremada, despossuída de bens econômicos e com frágeis vínculos sociais. O projeto teve por objetivo a criação de um espaço que possibilitasse o desenvolvimento de práticas complementares à educação regular ministrada nas instituições educacionais. Ao longo do projeto havia o hábito de registrar sem pretensão acadêmica ou artística, em uma máquina digital, cenas do cotidiano de nosso trabalho. Imbuídos de curiosidade a respeito das possibilidades do registro fotográfico capturamos uma sequência de fotos e a partir daí consideramos a fotografia como jogo de linguagem para entender uma realidade social.
\end{abstract}

Palavras-Chaves: Ceval; fotografia; jogo de linguagem.

\section{Resumen}

Nuestro estudio se realizó sobre un recorte de la realidad, utilizando fotografías, del proyecto de extensión sobre refuerzo escolar que se insertó en el programa de extensión, entre los años 2006 y 2010, "Acción interdisciplinaria de atención integral a los carretero y recolectores de residuos que trabajan en las orillas del arroyo Santa Bárbara en la ciudad Pelotas" bajo la responsabilidad de la Facultad de Veterinaria/UFPel y FaE/UFPel. La comunidad sigue caracterizándose por una vulnerabilidad social extrema, desposeída de bienes económicos y con vínculos sociales frágiles. El proyecto pretendía crear un espacio que permitiese el desarrollo de prácticas complementarias a la educación regular enseñada en instituciones educativas. A lo largo del proyecto existía el hábito de registrarse sin pretensión académica o artística, en una máquina digital, escenas de la vida cotidiana de nuestro trabajo. Imbuido de curiosidad por las posibilidades del registro fotográfico capturamos una secuencia de fotos y desde allí consideramos la fotografía como un juego de lenguaje para entender una realidad social.

Palabras claves: Ceval; fotografia; juego de lenguaje.

\footnotetext{
${ }^{1}$ Doutora em Filosofia pela Pontifícia Universidade Católica do Rio Grande do Sul; Porto Alegre; RS; Brasil, profa.heloisa.duval@gmail.com
} 


\begin{abstract}
Our study was held about a clipping of reality, using photographs, from the extension project on school reinforcement that was inserted in the extension program, between the years 2006 and 2010, "Interdisciplinary action of integral attention to cartwright and waste pickers working on the banks of the Santa Barbara creek in Pelotas" under the responsibility of the Faculty of Veterinary/UFPel and FaE/UFPel. The community is still characterized as of extreme social vulnerability, dispossessed of economic goods and with fragile social bonds. The project aimed to create a space that would enable the development of complementary practices to regular education taught in educational institutions. Throughout the project there was a habit of registering without academic or artistic pretension, in a digital machine, scenes of the daily life of our work. Imbued with curiosity about the possibilities of photographic record we capture a sequence of photos and from there we consider photography as a game of language to understand a social reality.
\end{abstract}

Keywords: Ceval; photograph; game of language.

\title{
1. Introdução
}

Refletir sobre a realidade das crianças do Loteamento Ceval que vivem as margens do Arroio Santa Bárbara nos incita a muitos pensamentos. Pensamos sobre como o trabalho infantil é reconhecido hoje, no mundo contemporâneo. E, sobre as condições que envolvem as crianças e as comunidade de carroças para seu sustento. Diante do vasto panorama nosso estudo teve um recorte da realidade a partir do Projeto de Extensão sobre reforço escolar que estava inserido no Programa de Extensão “Ação interdisciplinar de atenção integral a carroceiros e catadores de lixo que trabalham às margens do arroio Santa Bárbara em Pelotas".

A comunidade ainda é caracterizada como de vulnerabilidade social ${ }^{2}$ extremada, despossuída de bens econômicos e com frágeis vínculos sociais, ou seja, o trabalho é precário e há fragilidade nos apoios relacionais, como diz Robert Castel. Nessa comunidade há um grupo significativo de crianças sem perspectiva social ${ }^{3}$, que apresentam sérios problemas no processo de escolarização, necessitando, dessa forma, atividades de reforço escolar. Esta proposição é de extrema relevância social, uma vez que o Estatuto da Criança e do Adolescente - ECA indica a prioridade social à infância ${ }^{4}$. Além disso, é um exercício de reflexão crítica acerca do ser no mundo das crianças e do trabalho que foi desenvolvido junto ao Programa de Extensão.

\footnotetext{
${ }^{2}$ Segundo o sociólogo francês Robert Castel: “A zona de vulnerabilidade compreende pequenos trabalhadores independentes sem reservas econômicas (mercadores, ambulantes...) e um salariato precário de trabalhadores intermitentes do campo ou da cidade que não são assumidos pelo sistema corporativo, não se beneficiando de suas garantias (trabalhador manual, trabalhador sazonal, trabalhadores braçais diaristas ou por empreitada...) (Castel, 1997, p. 5-6).

${ }^{3}$ Robert Castel afirma que a vulnerabilidade social envolve vários processos de marginalização muitas vezes distanciando certo número de indivíduos de uma efetiva inserção social.

${ }^{4}$ Considera-se a infância o período que vai desde o nascimento até a idade pueril, aproximadamente doze anos. Não pretendemos aqui explorar a discussão sobre os aspectos sociais da mesma.
} 
Utilizaremos como fundamentação teórica o jogo de linguagem de Johan Joseph Ludwig Wittgenstein, mais conhecido como Wittgenstein, e a fotografia como uma forma de linguagem.

\section{O Loteamento Ceval e nossa experiência}

No ano de 2002 iniciou o movimento para apropriação de um terreno do poder público, por um recorte de população de renda baixíssima. Hodiernamente conhecido como Loteamento Ceval. De 2002 até 2006 as moradias eram precárias, mas a partir de 2006 a SMH (Secretaria Municipal de Habitação do município de Pelotas) constrói casas de um cômodo e um banheiro para essa comunidade. Seus moradores, em sua maioria, utilizam as carroças/charretes como meio de subsistência. A maioria vive de coleta de lixo seletiva, coleta de resíduos, pequenos fretes e também transporte familiar. Ainda nessas comunidades o cavalo é reconhecido como um bem, patrimônio familiar, assim como o terreno e a casa. Nessa comunidade há um grupo significativo de crianças e, tem-se desafio da permanência das crianças em idade escolar nos bancos escolares. O loteamento é composto originalmente por 177 casas e aproximadamente 1500 pessoas, hoje esse número mudou consideravelmente, pois há outros loteamentos no entorno com características semelhantes.

A atividade envolveu, então, 18 alunas que acompanhavam as lições de casa e orientavam os exercícios de reforço escolar, incentivando hábitos de escrita, de leitura, e também jogos educativos, atividades lúdicas e culturais, como também a elaboração de um documentário com a própria comunidade. Também tivemos o apoio de voluntários ao longo da execução do projeto, como: dentista, costureira, artesã, cabelereira, entre tantas pessoas. Essa experimentação de educação foi ímpar para as pessoas que participaram do projeto trazendo outras formas de olhar o exercício de cidadania.

\subsection{Situando a comunidade do Loteamento Ceval}

As comunidades de carroça na região de Pelotas são urbanas e, concentram na sua grande maioria pessoas que têm como fonte de renda atividades que envolvem as carroças. As carroças são de tração animal, ou seja, carroças conduzidas por cavalos. Dentre as atividades das comunidades de carroças podemos destacar as seguintes: coleta de resíduos, pequenos fretes e também transporte familiar. Ainda nessas comunidades o cavalo é reconhecido como um bem, patrimônio familiar, assim como o terreno e a casa. Em algumas visitas pudemos observar que a sala da casa era utilizada como baia para abrigar o cavalo, por ter esse um papel de grande importância na família e, não só como patrimônio material, 
mas também afetivo. O desafio da permanência das crianças em idade escolar nos bancos escolares constitui tarefa de suma importância às questões sociais que envolveram o reforço escolar dentro do programa de extensão “Ação interdisciplinar de atenção integral a carroceiros e catadores de lixo que trabalham às margens do arroio Santa Bárbara em Pelotas", neste programa estava envolvido também o Ambulatório Veterinário que ainda hoje atendem os animais domésticos e equinos dos carroceiros, como também da comunidade do entorno. Esta população envolvida, no atendimento do Ambulatório Veterinário da UFPel, vive abaixo da linha de pobreza e tem como principal fonte de renda a coleta do lixo que remanesce da cidade. Entre 2006 e 2007 a Assistente Social da UFPel, que integra o programa, Lenara Lamas Stelmake, realizou o levantamento socioeconômico da clientela ${ }^{5}$ carente às margens do arroio Santa Bárbara e utilizam o programa de extensão. O número revelado é de trezentas famílias, perfazendo um total de aproximadamente 1500 (mil e quinhentas) pessoas que vivem do sustento direto relacionado aos animais de tração. À época o levantamento socioeconômico apontou para necessidade de trabalhar com outras áreas de conhecimento já que, os moradores, pediram que algo fosse feito com as crianças, pois, eles, os adultos não tinham mais jeito (palavras de um dos moradores). Em 2008, a Profa. Dra. Heloisa Helena Duval de Azevedo, deu início ao projeto de reforço escolar como forma de consolidação do conhecimento e da prática ministrado nas escolas e na academia. A atividade envolveu, então, 18 alunas que acompanhavam as lições de casa e orientavam os exercícios de reforço escolar, incentivando hábitos de escrita, de leitura, e também jogos educativos, atividades lúdicas e culturais. Dessa forma as alunas do Curso de Licenciatura em Pedagogia ${ }^{6}$ desenvolveram as atividades de ensino, pesquisa e extensão, promovendo novos saberes que possibilitaram o exercício de cidadania, corroborando com a proposta da UFPel de compromisso social.

O reforço escolar justificou-se como mais uma possibilidade de construir processos educativos. É uma ação que enriquece a vida e a formação dos alunos e discentes, ou seja, suas experiências culturais e sociais criam espaços para que experimentem a educação de outras formas. O reforço escolar foi além da tentativa de solucionar dificuldades de aprendizagem, ampliando o conhecimento de alunos e professores, serviu como exercício de cidadania. O reforço escolar, além de propiciar aos discentes de Pedagogia a formação de extensionistas, promoveu o exercício de novos saberes e apontou para um olhar diante do mundo que pode estar apto a mudança. Um mundo de grande vulnerabilidade, mas também

\footnotetext{
${ }^{5}$ Palavras da Assistente Social Lenara Lamas Stelmake.

${ }^{6}$ Doravante Pedagogia.
} 
de muitas possibilidades desde que o enfoque seja a garantia dos direitos de cidadania das comunidades.

\subsection{O jogo de linguagem, o reforço escolar, a fotografia}

Nas primeiras páginas das Investigações Filosóficas Wittgenstein diz: “... nossa investigação não se dirige aos fenômenos, e sim, como poderia dizer, às 'possibilidades' dos fenômenos. Isto quer dizer que meditamos sobre a espécie de asserções que fazemos sobre os fenômenos." (Wittgenstein, 1996, p. 65). O que para ele interessa não é a apreensão imediata dos fenômenos e sim as afirmações que operamos sobre os fenômenos através da linguagem. Nas Investigações Filosóficas $§ 23$ Wittgenstein descreve o que é jogo de linguagem:

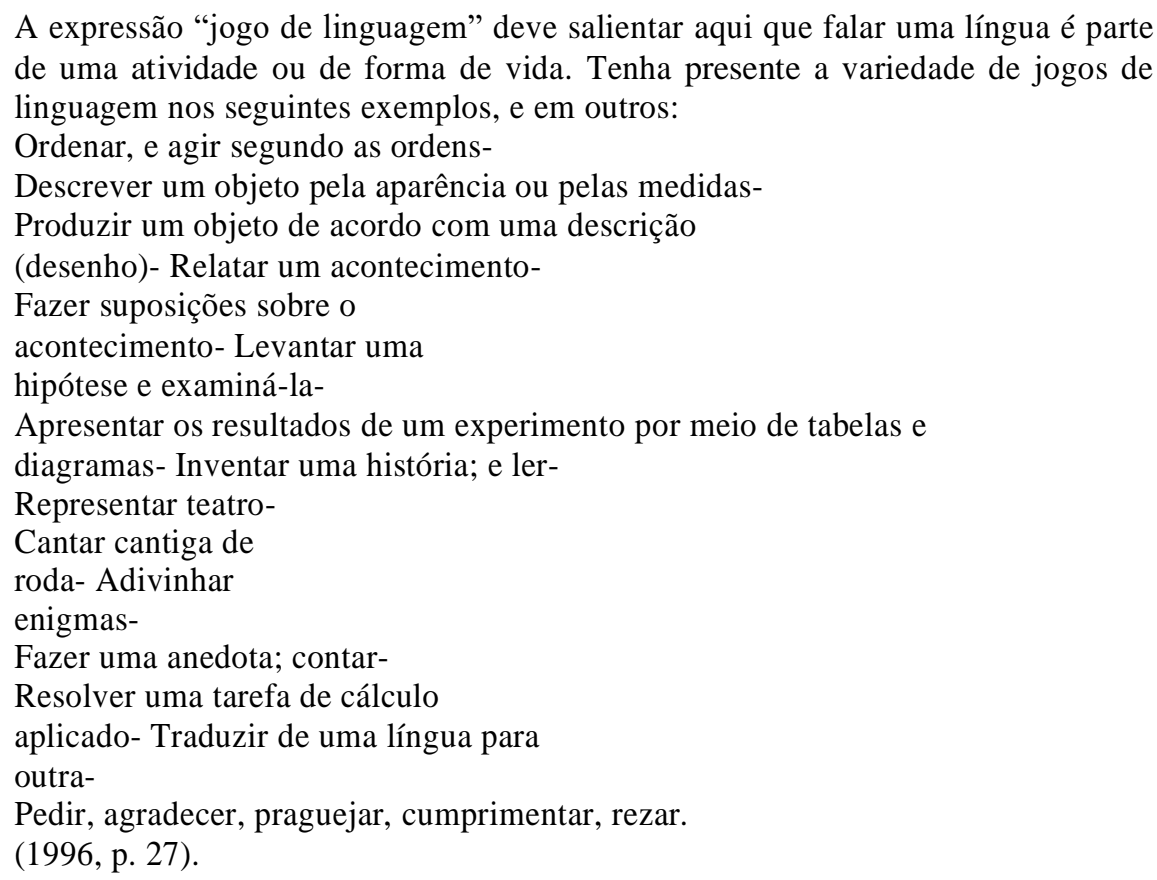

A relação mundo e linguagem das Investigações Filosóficas trazem a linguagem para o cotidiano. Ao contrário do Tractatus as Investigações Filosóficas colocam como centro da linguagem um mundo de uma comunidade linguística que interpreta. E, seus membros entendem a si mesmos, aos outros e ao mundo por meio do jogo da linguagem. Os jogos de linguagem geram múltiplas formas de convivência. O jogo é uma atividade, e a significação passa a ser a capacidade de seguir uma regra e de aprender a jogar cada jogo.

Para o Wittgenstein das Investigações Filosóficas a linguagem é uma forma de ação e de atividade. Uma atividade que envolve significação das formas de vida e cultura, ou ainda, uma rede de significações que envolve tanto a forma de vida quanto o que acreditamos 
enquanto cultura. Lembremos que foi a perspectiva social que levou Wittgenstein a modificar sua teoria e sua prática filosófica. Segundo o autor:

\begin{abstract}
Uma cultura é como uma grande organização que atribui a cada um de seus membros um lugar em que ele pode trabalhar no espírito do conjunto; e é perfeitamente justo que o seu poder seja medido pela contribuição que consegue dar ao todo. Numa época sem cultura, por outro lado, as forças tornam-se fragmentárias e o poder do indivíduo consome-se na tentativa de vencer forças opostas e resistências ao atrito; tal poder não é visível na distância que percorre, mas unicamente no calor por ele produzido ao vencer o atrito (WITTGENSTEIN, 1980, p. 20).
\end{abstract}

Trazemos à memória que o movimento da virada linguística traz como consequência diferentes determinações ou rumos de possíveis aplicações em se tratando da análise da categoria cultura, bem como uma nova proposta de enxergar o mundo a partir dos jogos de linguagem. Só um indivíduo engajado que pertença ao mundo pode modificá-lo. Ou ainda como diria Wittgenstein, segundo Baker e Hacker:

[...] uma linguagem é um aspecto da ação humana, enraizada no comportamento humano. Ela não surgiu a partir de algum tipo de raciocínio. Falar é agir; e verbalizar palavras e sentenças está entrelaçado a atividades humanas que ocorrem dentro do mundo do qual somos parte. Uma linguagem em uso é parte de uma forma de vida" $(1984, \S 133)$.

Isso denota que para conhecer o que está por trás de um significado convém conhecer o contexto da atividade em que esse está inserido, pois a significação não é só um exercício metafísico, pelo contrário, o exercício da mesma por meio da a linguagem e o processo de significar fazem parte de uma forma de vida, ou seja, da mundanidade pertencente a um mundo prático.

\title{
2.3. A fotografia como um jogo de linguagem cotejador
}

Tínhamos o hábito de registrar sem pretensão acadêmica ou artística, em uma máquina digital, cenas do cotidiano de nosso trabalho. Em um dia que ocorriam em paralelo o reforço escolar e o atendimento do Ambulatório Veterinário, do programa de Atenção Integral aos Carroceiros, da Faculdade de Veterinária da UFPel na cidade de Pelotas, surge um guri ${ }^{7}$ curioso. E, imbuídas de uma curiosidade a respeito das possibilidades do registro fotográfico capturamos a seguinte sequência:

\footnotetext{
${ }^{7} \mathrm{O}$ termo guri é usado na região sul do Brasil, mais especificamente, no estado do Rio Grande do Sul e significa menino ou criança do sexo masculino. 


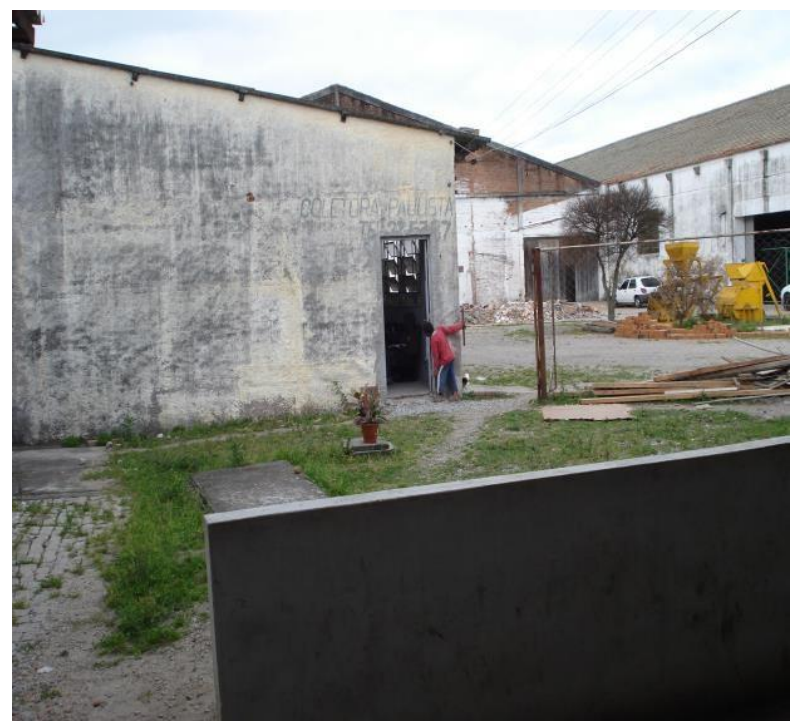

Fotografia 1 - Guri espiando a sala de aula. Fonte: acervo pessoal.

A primeira fotografia registra o momento em que o guri observava a movimentação das crianças para iniciar as atividades de reforço escolar. Nós ficamos atentas a movimentação dele. Não o forçamos a entrar e ficamos esperando o que iria fazer. $\mathrm{O}$ guri ficou boa parte da manhã espreitando as atividades na sala de aula. E em determinado momento decidiu entrar e falar com as extensionistas que trabalhavam no projeto. As imagens seguintes foram disparadas ao acaso e só depois percebemos que faziam parte de uma mesma linguagem, eis:

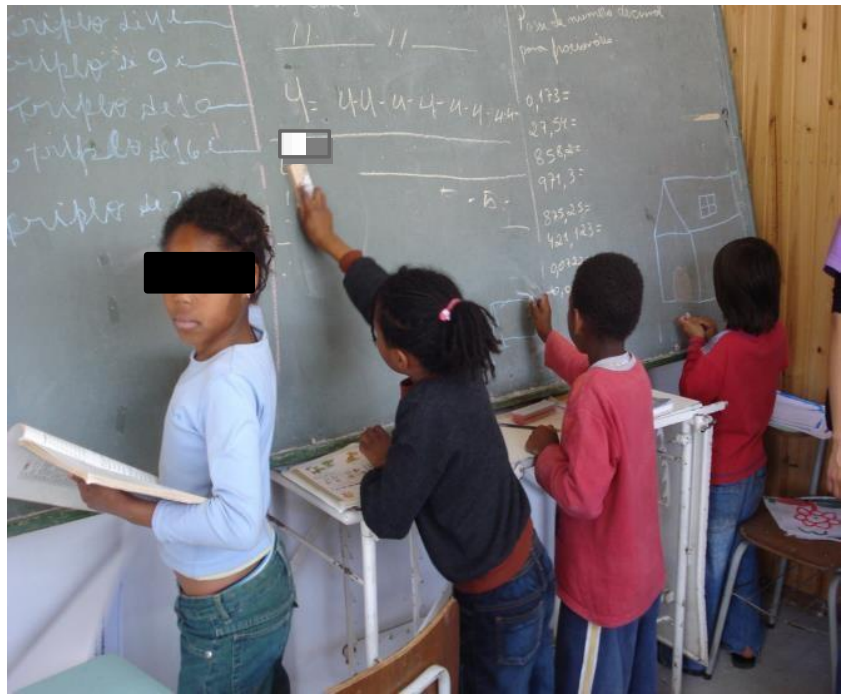

Fotografia 2 - Guri participando das atividades do reforço escolar. Fonte: acervo pessoal. 
Nesta segunda fotografia da sequência o guri aparece ao lado dos colegas realizando os exercícios propostos pelas extensionistas. Considerando que nem todas as crianças se conheciam, até o momento de participar do projeto de reforço escolar, observamos que o entrosamento do guri ocorreu rapidamente com os colegas e de maneira natural, conforme apresentamos na fotografia abaixo:

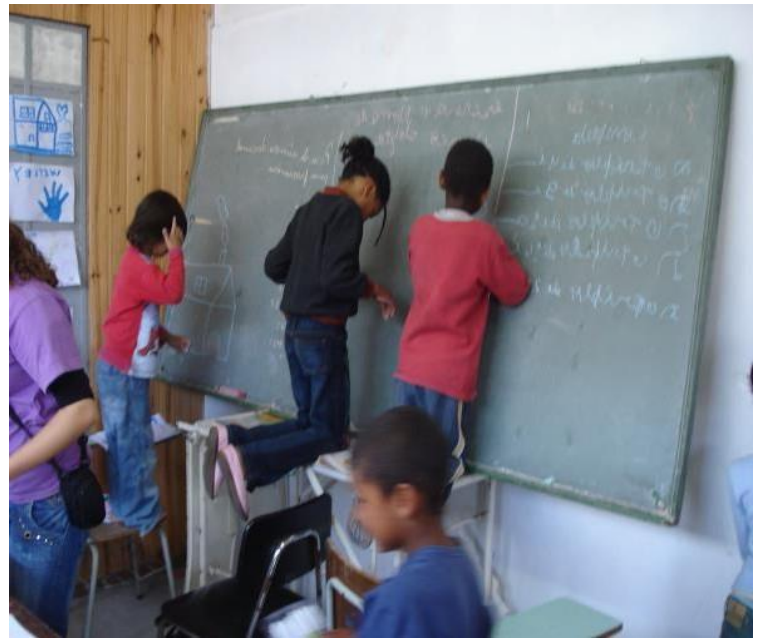

Fotografia 3 - Guri à mesa escrevendo no quadro negro. Fonte: acervo pessoal.

Na terceira fotografia da sequência o guri está de joelhos sobre a mesa e escrevendo no quadro negro. $\mathrm{O}$ quadro negro estava improvisadamente apoiado sobre uma mesa de metal. Esta sala nos serviu em um momento de transição para outro espaço maior. Poderíamos utilizar esta sequência e interpretá-la de maneiras distintas. Não é que faremos. As fotografias são utilizadas como recurso de um jogo de linguagem para entender uma realidade social.

A realidade social apontada por meio de uma fotografia nos fez exercitar a percepção das cores como, por exemplo, uma realidade saindo de foco e outra inventada. Jogamos com as cores e seus significados: o cinza da parede pode dizer não, o vermelho da blusa do menino pode dizer sim... eu posso, eu quero, eu vou, eu entrei, eu consegui. É nossa subjetividade interpretando outra realidade. E, com a convivência podemos afirmar que estamos em um mesmo jogo de linguagem. Poderíamos nos perguntar, assim como Wittgenstein, $\S 71$, se o conceito jogo não é um conceito impreciso (1994, p. 54) e se o recurso da fotografia embaçaria nossa reflexão. Como diria Wittgenstein, § 71:

Mas um conceito impreciso é, por acaso, um conceito? -Uma fotografia desfocada é, por acaso, o retrato de uma pessoa? Bem, pode-se substituir sempre com vantagem um retrato desfocado por nítido? Freqüentes vezes não é o retrato desfocado precisamente aquilo de que mais precisamos? (1994, p. 54). 
O instante em que a fotografia foi tirada não pode ser capturado novamente. Mesmo se conseguirmos reproduzi-la mecanicamente nunca poderemos reproduzi-la existencialmente (Barthes, 2008, p. 12). E, segundo os autores:

\begin{abstract}
Surge assim, no interior da fotografia, um instante por ela simbolizado e diferente do instante em que a fotografia foi tirada. Esse instante interno, que necessita da técnica do instantâneo, mas não é ele mesmo o instante técnico do disparo fotográfico, é parte fundamental de uma linguagem que Cartier-Bresson formulou para a fotografia. Uma linguagem que não apenas se vale do instantâneo, mas que também o significa. E dado que o significa pela rápida relação entre similaridades que provoca no olhar do espectador, instantaneidades e semelhanças visuais - entre seres, pessoas, coisas no mundo - formam arranjos os mais variados e surpreendentes numa das mais poéticas artísticas mais plenas do século XX (MAMMI E SCHWARTZ, 2008, p. 10).
\end{abstract}

A ideia de Barthes é de que não conseguimos reproduzir uma fotografia existencialmente, mas podemos “... reconciliar a Fotografia com a sociedade (é necessário? Pois bem, sim: a Foto é perigosa), dotando-a de funções que são, para o Fotógrafo, outros tantos alibis (sic). Essas funções são: informar, representar, surpreender, dar significação, provocar desejo (2008, p. 37). Barthes e Cartier-Bresson enfatizam o dar significação à fotografia. Aí encontramos um ponto de proximidade com o jogo de linguagem de Wittgenstein. A significação “... não se dá mais pela correspondência entre mundo e pensamento, e sim por uma ligação por meio da prática ou do uso da própria linguagem, ou seja, pela aplicação da linguagem" (AZEVEDO, 2009, p. 66). É no cotidiano que encontramos significado atrelado às nossas relações.

\title{
2.4. O guri da comunidade de carroça
}

As novas tecnologias trouxeram magníficos avanços na área da saúde, da educação, da política e da informática, com isso, ganhamos em conforto e bem-estar, mas, existe um outro lado. Paralelamente aos benefícios do ideário da modernidade temos a miséria, o trabalho braçal, a inexistência de acesso a direitos como cidadão como resultado da desigualdade social. O projeto de reforço escolar dentro do Programa de Extensão "Ação interdisciplinar de atenção integral a carroceiros e catadores de lixo que trabalham às margens do arroio Santa Bárbara em Pelotas" contemplou por um período as crianças e os adolescentes que residiram às margens do arroio Santa Bárbara na cidade de Pelotas. Em nosso percurso de troca de conhecimento descobrimos que, na cidade de Pelotas há pouco ou nada sobre o assunto da relação entre o guri e o cavalo. Sabemos que a desigualdade social e a miséria impulsionam o trabalho infantil, contudo, observamos que tanto as famílias quanto as crianças e os adolescentes atrelam justificativas de teor econômico e razões de caráter 
subjetivo para desempenharem o papel ativo junto à comunidade de carroça. Nesse sentido, a cultura regional é facilitadora da diluição do conceito e da prática do que é trabalho infantil nas comunidades de carroça.

Os guris e as gurias que frequentaram o projeto de reforço escolar têm uma relação muito próxima com cavalos, pois vivem junto deles e também há questões formadoras e históricas em que o cavalo agrega ao homem poder e autoestima. No imaginário popular regional, a figura do cavalo sempre está presente, seja num desfile Farroupilha ${ }^{8}$, nas brincadeiras de criança com o cavalo-de-pau, nas lendas gaúchas - entre elas o Negrinho do Pastoreio - e mesmo nas lutas históricas, como a guerra dos Farrapos. Desta forma nos permitimos dizer que a presença do cavalo é constante em nossas vidas, mesmo nas zonas urbanas e do mundo $\mathrm{Hi}$-Tech uma vez que a cultura do cavalo faz parte da riqueza cultural e histórica no Rio Grande do Sul.

A linguagem nestas comunidades é particularmente diferente, tem gestos, vocabulário próprio, interpretação do cotidiano, muito com recortes do mundo rural. Estas crianças ainda inventam seus brinquedos como uma lanterna, feita de garrafa pet e com o inseto vaga-lume, o carrinho de lomba (onde não há lomba já que Pelotas é uma cidade plana), mas o grande poder é o trato com o cavalo, cavalo que significa liberdade, mundo aberto, ao contrário muitas vezes da escola que se fecha para eles. Um exemplo deste mundo do guri relacionado ao cavalo: - uma aluna da graduação em Pedagogia, que foi extensionista, reuniu as crianças e contou a história da Cinderela. Ao final da leitura pergunta o que falta? Considerando o sapato de cristal, claro! Um guri responde: - os arreios do cavalo professora! Esse é o mundo deles.

O vínculo social destas comunidades é extremamente frágil. A natureza do vínculo na contemporaneidade, numa perspectiva pós-moderna, propõe o jogo de linguagem como um método a ser seguido. Para Lyotard: “... a questão do vínculo social, enquanto questão é um jogo de linguagem, o da interrogação, que posiciona imediatamente aquele que a apresenta, aquele a quem ela se dirige, e o referente que ela interroga: essa questão já é assim o vínculo social" (2008, p. 29). E, somos surpreendidos com a beleza da afirmação de uma criança...

\footnotetext{
${ }^{8}$ Em 20 de setembro de 1835 iniciou a guerra dos Farrapos ou revolução Farroupilha, que durou 10 anos. No estado do Rio Grande do Sul essa data é comemorada pelo fato de ser a mis longa revolução no Brasil e ter como ideário a igualdade, a liberdade e a humanidade.
} 


\title{
3. Considerações Finais
}

Por que fotografamos? Para documentar, guardar pedacinhos do nosso olhar, sentimentos, sensações, também para falar através do silêncio ou o silêncio falar por nós, para falar através de imagens ou para as imagens falarem por nós? Ou ainda podemos nos inspirar em Degas e falarmos dos heróis, cuja armadura é tão exata:

\begin{abstract}
Degas encontrava no cavalo de corrida um tema raro, que satisfazia às condições que sua natureza e sua época impunham às escolhas. Onde encontrar algo puro na realidade moderna? Ora, o realismo e o estilo, a elegância e o rigor viam-se combinados no ser luxuosamente puro do animal de raça. Aliás, nada poderia seduzir mais um artista tão refinado, tão difícil e amante de preparações longas, de seleções sutis e do fino trabalho de adestramento, do que essa obra-prima angloárabe. Degas amava e conhecia o cavalo de sela a ponto de reconhecer o mérito de artistas muito distantes dele quando encontrava o cavalo bem estudado em sua obra. Um dia, na casa de Durand-Ruel, ele me reteve durante muito tempo na frente de uma estatueta de Meissonier, um Napoleão eqüestre em bronze, de cerca de trinta centímetros de altura, e detalhou para mim as belezas, ou melhor, as exatidões que reconhecia naquela pequena obra. Canelas, quartelas, boletos, postura, garupa... Tive de escutar toda uma análise crítica e finalmente elogiosa. Louvou igualmente o cavalo de Joana d'Arc de Paul Dubois, que se encontra em frente à igreja de SaintAugustin. Esqueceu de falar da heroína, cuja armadura é tão exata (VALERY, 2012, p. 82).
\end{abstract}

Esse trabalho envolveu um grupo constituído para além da comunidade de professores e alunos ligados à um curso de graduação. O grupo foi imbuído, não só pelo tripé que constituiu uma universidade, mas pelos heróis anônimos e pelo exercício de cidadania próprio na natureza humana consciente da existência do outro.

\section{Referências}

AZEVEDO, Heloisa Helena Duval de Azevedo. O viés austríaco da virada linguística. In: AZEVEDO, Heloisa Helena Duval de Azevedo; OLIVEIRA, Neiva Afonso; GHIGGI, Gomercindo. Interfaces: temas de educação e filosofia. Pelotas: Editora e gráfica universitária/UFPel, 2009. p. 55-69. (Capítulo de livro)

BAKER, G.P. \& HACKER, P.M.S. Scepticism, Rules and Language. Oxford: Basil Blackwell, 1984. (Obra completa)

BARTHES, Roland. A câmara clara: notas sobre a fotografia. Lisboa: Edições 70, 2008. (Obra completa)

CASTEL, Robert. A dinâmica dos processos demarginalização:da vulnerabilidade a "desfiliação". Caderno CRH, Salvador, n. 26/27, p. 19-40, jan./dez. 1997. Disponível em:<http://www.cadernocrh.ufba.br/viewarticle.php?id=193>. Acesso em: 20 set. 2017. (Artigo em periódico digital) 
LYOTARD, Jean-François. A condição pós-moderna. Rio de Janeiro: José Olympio, 2008. (Obra completa)

MAMMI, Lorenzo, SCHWARCZ, Lilian Moritz. 8 X fotografia. São Paulo: Companhia das Letras, 2008. (Obra completa)

VALERY, Paul. Degas: dança desenho. São Paulo: Cosacnaify, 2012. (Obra completa) WITTGENSTEIN, Ludwig. Investigação Filosóficas. Petrópolis: Vozes, 1994. (Obra completa) 